\title{
COVID-19 in children: patiently and critically evaluate the scientific evidence
}

\author{
Nicole Ritz ${ }^{1,2} \cdot$ J. Peter de Winter ${ }^{3,4}$ \\ Published online: 3 June 2020 \\ (C) Springer-Verlag GmbH Germany, part of Springer Nature 2020
}

Since December 2019, a new disease is challenging us in an unprecedented manner. The novel coronavirus SARS-CoV-2 has rapidly spread worldwide and infected at least 5 million individuals in less than five months. We are in the middle of the most serious global health crisis since the emergencence of the epidemic caused by the human immunodeficiency virus in the 1980s. Usually, we manage our patients and give recommendations in an evidence-based way; however, in these novel times, we have little evidence at our disposal. Also, the speed and amount of mainstream and social media sharing information which has not been reviewed in a scientific rigour is challenging us further.

So how do we move forward as clinicians, researchers, and policymakers in the coming months? First of all, we have to integrate our response into the emerging evidence and keep principles of scientific rigour and peer-review at the highest level despite the time pressure. So far, the majority of COVID19 cases occurred in adults and particularly in older adults so the disease in children has been less well described [1]. It this therefore important to publish data on large case series from all countries worldwide. We published an Italian series by Parri and co-authors that shows the clinical spectrum of pediatric COVID-19 including severe and critical cases in $15 \%$ of the patients [2]. Importantly, infants less than six months of age seem at increased risk. So while the risk factors from

Nicole Ritz

Nicole.ritz@unibas.ch

1 Paediatric Infectious Diseases and Vaccinology, University of Basel Children's Hospital (UKBB), Spitalstrasse 33,

CH-4031 Basel, Switzerland

2 Department of Paediatrics, The University of Melbourne, Parkville, Victoria, Australia

3 Department of Paediatrics, Spaarne Gasthuis Hoofddorp/Haarlem, Hoofddorp/Haarlem, The Netherlands

4 Department of Development and Regeneration, KU Leuven, Leuven, Belgium
COVID-19 in adults have been well described so far, including obesity, hypertension, and older age [3], such factors remain to be determined in children [4].

Further to this, regular, systematic reviews will be required, and the challenge will be to strike the right time to summarise current data. The international database of prospectively registered systematic reviews (PROSPERO) lists as of 26 May 2020 more than 1000 systematic reviews on COVID-19 of which more than 200 included children. Several systematic reviews were published, including in pediatrics [1,5-7] with still limited numbers of children included. The first systematic review published in the European Journal of Pediatrics by Liguora and colleagues includes 62 pediatric studies published by 1 May 2020 including 7480 children and confirms the mild to moderate spectrum of the disease [8]. Importantly in one fifth of the cases, the children had an underlying illness with lung disease including asthma, congenital heart disease, and hematooncological disease being most frequently described.

Finally, it will also be essential to collect data in children in larger national and international registries, as COVID-19 will be too rare in smaller countries and ethnic factors may play a role in the disease severity. A further study selected for publication by the European Journal of Pediatrics describes the set-up and aim of one for the currently establishing networks called EPICENTER to gain further insight into this disease [9]. As a famous proverb phrases it: if you want to go fast, go alone; if you want to go far, go together. Paediatric COVID-19 requires a fast response but also a long-term perspective, and we will be keen to see results from the EPICENTER and other registries being published in the coming months in the European Journal of Pediatrics.

Authors' Contributions NR and PJdW have drafted and revised the final version of the manuscript.

\section{References}

1. Tagarro A, Epalza C, Santos M, Sanz-Santaeufemia FJ, Otheo E, Moraleda C, Calvo C (2020) Screening and severity of coronavirus 
disease 2019 (COVID-19) in children in Madrid, Spain. JAMA Pediatr. https://doi.org/10.1001/jamapediatrics.2020.1346

2. Parri et al (2020) Characteristic of COVID-19 infection in pediatric patients: early findings from two Italian Pediatric Research Networks. Eur J Pediatr. https://doi.org/10.1007/s00431-020-03683-8

3. Zheng Z, Peng F, Xu B, Zhao J, Liu H, Peng J, Li Q, Jiang C, Zhou Y, Liu S, Ye C, Zhang P, Xing Y, Guo H, Tang W (2020) Risk factors of critical \& mortal COVID-19 cases: a systematic literature review and meta-analysis. J Infect. https://doi.org/10.1016/j.jinf. 2020.04.021

4. Jayaraj R, Kumarasamy C, Shetty SS, Ram MR, Shaw P (2020) Clinical and conceptual comments on "Risk factors of critical \& mortal COVID-19 cases: A systematic literature review and metaanalysis". J Infect. https://doi.org/10.1016/j.jinf.2020.05.011

5. Parri N, Lenge M, Buonsenso D, Coronavirus Infection in Pediatric Emergency Departments Research G (2020) Children with Covid-19 in Pediatric Emergency Departments in Italy. N Engl J Med. https:// doi.org/10.1056/NEJMc2007617

6. Zimmermann P, Curtis N (2020) COVID-19 in children, pregnancy and neonates: a review of epidemiologic and clinical features. Pediatr
Infect Dis J 39(6):469-477. https://doi.org/10.1097/INF. 0000000000002700

7. Zimmermann P, Curtis N (2020) Coronavirus infections in children including COVID-19: an overview of the epidemiology, clinical features, diagnosis, treatment and prevention options in children. Pediatr Infect Dis J 39:355-368. https://doi. org/10.1016/j.jinf.2020.05.011

8. Liguoro I, Pilotto C, Bonanni M, Ferrari ME, Pusiol A, Nocerino A, Vidal E, Cogo P (2020) SARS-COV-2 infection in children and newborns: a systematic review. Eur J Pediatr. https://doi.org/10. 1007/s00431-020-03684-7

9. De Luca D, Rava L, Nadel S, Tissieres P, Gawronski O, Perkins E, Chidini G, Tingay DG (2020) The EPICENTRE (ESPNIC Covid pEdiatric Neonatal Registry) initiative: background and protocol for the international SARS-CoV-2 infections registry. Eur J Pediatr:1-8. https://doi.org/10.1007/ s00431-020-03690-9

Publisher's note Springer Nature remains neutral with regard to jurisdictional claims in published maps and institutional affiliations. 